\section{Design of the torus interface for the neutral beam injectors of Wendelstein 7-X}

\author{
R. Nocentini, B. Heinemann, R. Riedl, N. Rust, \\ G. Orozco \\ Max-Planck-Institut für Plasmaphysik, \\ Boltzmannstrasse 2, D-85748 Garching, Germany \\ riccardo.nocentini@ipp.mpg.de
}

\begin{abstract}
A neutral beam injection (NBI) heating system for the stellarator project Wendelstein 7-X (W7-X) is currently under construction at the Max Planck Institute for Plasma Physics (IPP) Greifswald, Germany. The $\mathrm{NBI}$ at W7-X is based on the similar system in operation on the tokamak ASDEX Upgrade at IPP in Garching, Germany, and makes use of radio-frequency-driven positive ion sources. Two NBI injectors are going to be installed in W7-X, each being capable of hosting four ion sources. Initially each injector is being equipped with two ion sources of 1.8 (2.5) MW beam power each in $\mathrm{H}(\mathrm{D})$. Accelerated positive ions are going to be neutralized and transported inside an NBI-box, which also hosts a residual ion dump, titanium sublimation pumps and a calorimeter. The beams are focused at a point $6.5 \mathrm{~m}$ downstream of the ion sources and are injected into the plasma vessel of W7-X through two ports. The NBI boxes and their NBI ports are connected by NBI-torus interfaces, which are made of several components that minimize beam losses while protecting the port walls and bellows from energetic re-ionized particles and beam intersection. This paper describes the design of the NBI-torus interface, including the shape optimization of a beam scraper and the integration of beam diagnostics.
\end{abstract}

\section{Introduction}

The fusion experiment Wendelstein 7-X (W7-X), the largest stellarator project to date, is currently under construction at the Greifswald branch of IPP, in Mecklenburg-Western Pomerania, Germany [1][2]. W7-X is planned to start plasma operation in 2015. The goal of this new machine is to demonstrate that the stellarator concept is suitable as an alternative to the tokamak concept on the way to a future fusion power plant. W7-X is a superconducting stellarator with nonplanar and planar coils arranged in 5 equal modules. An outer vessel (OV), or cryostat, contains the superconducting magnets at cryogenic temperature. Each module is made of two flip-symmetric half-modules. The hot fusion plasma is going to be generated and maintained inside a plasma vessel (PV) by means of electron cyclotron resonance heating (ECRH) and neutral beam injection (NBI) heating systems, with the option to install also ion cyclotron resonance heating. The NBI heats the plasma by injection of fast neutral hydrogen (or deuterium) atoms. The NBI system for W7-X consists of two injectors which can host up to 4 JET-type PINI (plug-in neutral injector) ion sources [3] arranged in a rectangle on the back side of the injection boxes. Initially the two injectors are going to be equipped with two PINIs, with 1.8 (2.5) MW beam

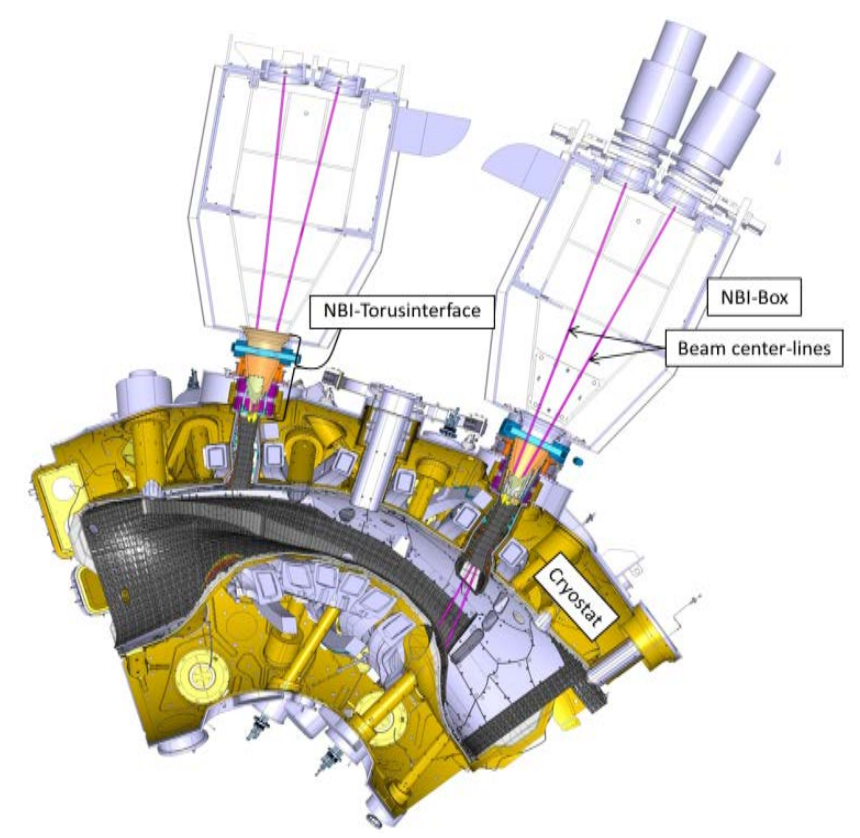

Figure 1: Top view of the port regions of the two neutral beam injectors of W7-X, left is the NI21, right the NI20 injector, each equipped with two sources. 
power each and $55(60) \mathrm{kV}$ acceleration voltage in $\mathrm{H}(\mathrm{D})$, with pulsed operation: $10 \mathrm{~s}$ beam, every 3 minutes [3].

The design of the W7-X NBI system is largely based on the positive ion system which is being operated

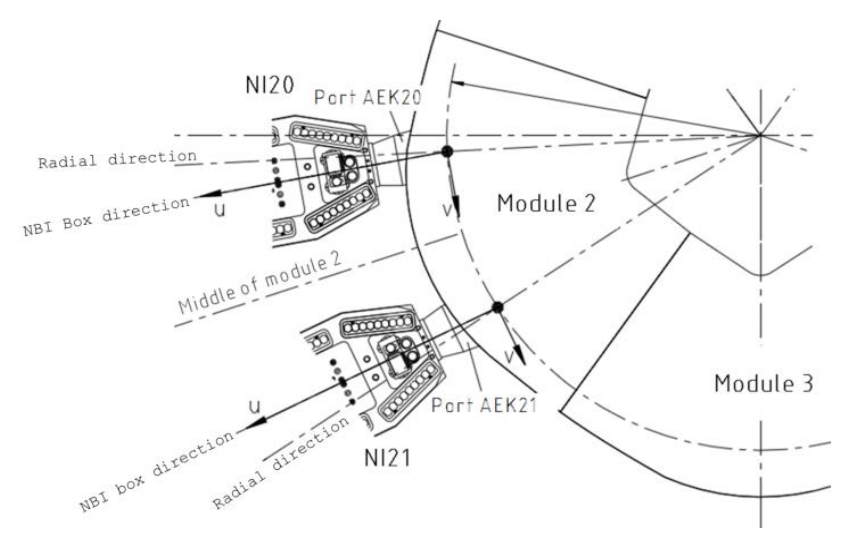

Figure 2: Scheme of position and orientation of the 2 NBI injectors with respect to the module 2 of W7-X.

at the ASDEX Upgrade (AUG) tokamak at IPP Garching, Germany, since 1992 [5][6] and will use radio-frequency-driven ion sources, already used in one of the AUG NBI-injectors. The beams are accelerated, neutralized and transported inside an NBI box, where a residual ion dump, an enhanced titanium sublimation pump [7] and a retractable calorimeter will be installed.

The two injectors are both connected to the module no. 2 on the ports AEK20 and AEK21 of W7-X, in the position shown in Figure 1 and Figure 2. The NBI boxes are positioned in such a way that for each injector two sources inject almost radially in the torus, while the other two inject more tangentially [8], with the possibility of a balanced injection with zero net plasma current. The beam is transported into the PV of W7-X through the NBI-torus interface and the NBI port, shown in Figure 3.

As a consequence of the complex W7-X machine geometry and of the tightly packed planar and nonplanar superconducting coils, the space available for the NBI port is very limited. These constraints have proved challenging for the mechanical and thermal design of the NBI-torus interface components. In addition, the complex movements of the PV and OV during several operation scenarios, e.g. baking of the PV, had to be taken into account. The dimensional and operational constraints for the design of the NBI-torus interface are discussed in Section 2.

The NBI-torus interface is composed of a DN $800 \mathrm{~mm}$ gate valve, described in Section 3, which includes a baking system and an electrical insulation between NBI box and gate valve, and an "NBI bellows unit”, see Section 4, which connects the NBI box to the OV.

A borescope and $\mathrm{H}_{\alpha}$ diagnostic have been integrated in each NBI bellows unit to monitor the NBI port and PV wall heat shields and to stop the beams in case beam blocking occurs, as discussed in Section 5.

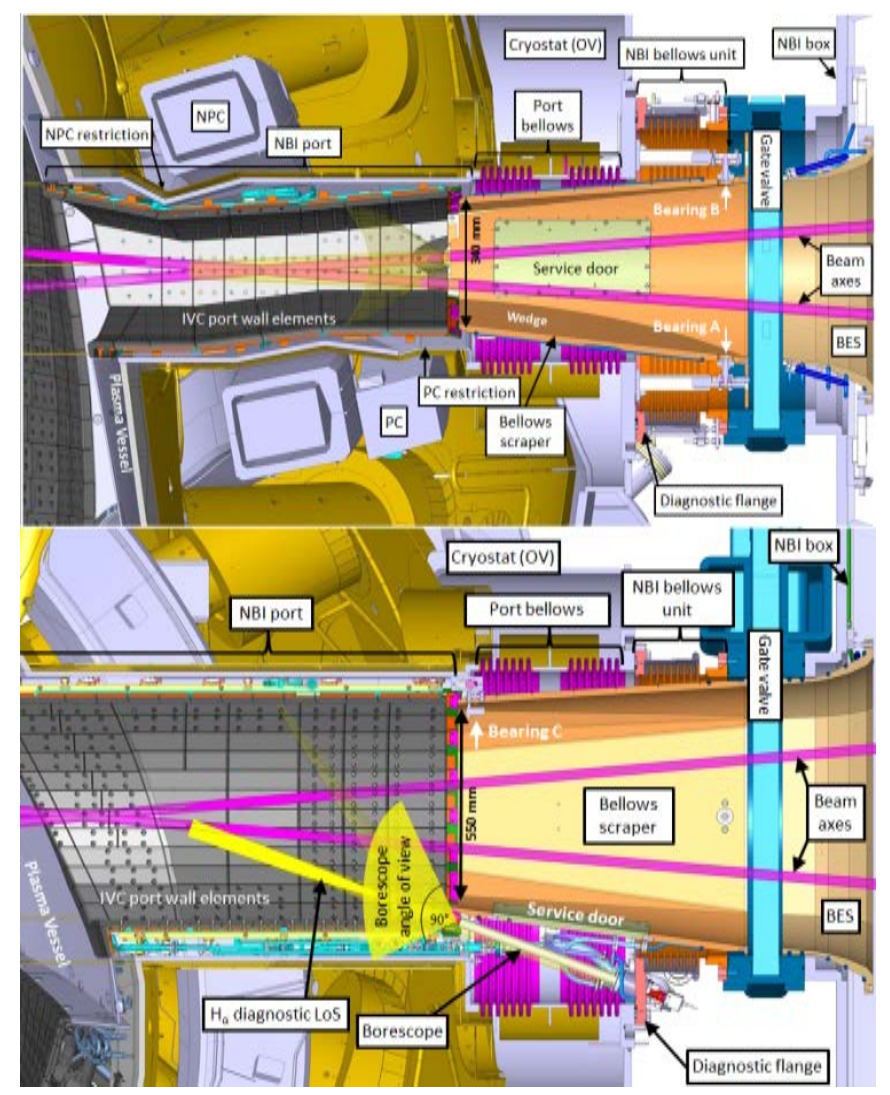

Figure 3: Horizontal section (top) and vertical section (bottom) of the NI21 port and torus interface. The non-planar coil (NPC) and the planar coil (PC) around the NBI port considerably limit the available space. The $90^{\circ}$ angle of view of the borescope is indicated schematically by the yellow fan. 
The NBI port and the OV are connected by a port bellows to allow for relative movements. In order to reduce the power loads on port walls and bellows, a box exit scraper (BES) has been installed at the exit of the NBI box to scrape off the outer edges of the beams. The NBI bellows and port bellows are protected by a "bellows scraper". Both BES and bellows scraper are inertially cooled and are described in detail in Sections 6 and 7 respectively. The bellows scraper is supported by a self-adjusting system of joints and hinges to compensate for relative displacements between NBI port (fixed to the PV) and OV during several operating scenarios. In this way it was possible to avoid reducing further the narrow cross section of the port in order to hide the leading edges for all possible port movements. A significant effort has been undertaken to optimize the shape of the bellows scraper minimizing its maximum temperature at the end of a beam pulse, as discussed in Section 7.1. In particular the peak power density has been reduced by distributing the beam power load over a larger surface, with a more convenient angle of impact, and the thickness of the bellows scraper has been increased in the area of higher heat load.

Further downstreams the NBI port is shielded by invessel components (IVCs), inertially cooled graphite and CFC-protected heat shields that are designed for heat loads of up to $6.3 \mathrm{MW} / \mathrm{m}^{2}$ for $10 \mathrm{~s}$ pulse length [8]. In case of low plasma density, a significant portion of the beam is not absorbed by the plasma and can "shine through" onto the inner plasma vessel wall, which is also protected by dedicated IVCs [9].

\section{Dimensional and operational constraints for the he NBI-torus interface}

The cross section of the NBI port, shown in Figure 3 , is about $340 \mathrm{~mm}$ wide and $550 \mathrm{~mm}$ high at the narrowest point, while the total length of the port is

1 Positive elongation means compression of port bellow, negative elongation means expansion of port bellow. about $2 \mathrm{~m}$. The components of the NBI-torus interface have been designed for operation with a fully equipped NBI injector (4 PINIs), i.e. four neutral beams with a total power of $10 \mathrm{MW}$ (D) for $10 \mathrm{~s}$ are transported through this narrow duct. The four beams are produced by the ion sources in the back of the NBI box and converge with horizontal and vertical angles of $\pm 4.1^{\circ}$ and $\pm 4.9^{\circ}$ respectively, with respect to the NBI-box axis. Each single beam diverges about $1^{\circ}[3]$.

Depending on the operating scenarios of W7-X, large displacements of PV and OV can take place. The largest relative movement of PV with respect to the $\mathrm{OV}$ is due to the thermal expansion of the PV during bakeout. In this scenario the NBI port moves axially (beam direction) toward the OV by $20 \mathrm{~mm}$ and $24 \mathrm{~mm}$ for the port AEK20 and AEK21 respectively. In addition a PVOV relative lateral movement of $9 \mathrm{~mm}$ and $8 \mathrm{~mm}$ is calculated for ports AEK20 and AEK21 respectively. The relative movements between $\mathrm{PV}$ and $\mathrm{OV}$ are compensated by the port bellows.

Table 1 Displacements of PV and OV due to several operation scenarios. Values are in mm. A safety factor of 1.5 has been considered in the calculations. Courtesy of P. van Eeten.

\begin{tabular}{cccc}
\hline & Ports & AEK20 & AEK21 \\
\hline PV-OV relative & $\begin{array}{c}\text { Maximum } \\
\text { elongation }\end{array}$ & -20 & -24 \\
displacements & Maximum lateral & 5 & 3 \\
\hline offset & 9 & 8 \\
\hline $\begin{array}{c}\text { OV-NBI relative } \\
\text { displacements }\end{array}$ & $\begin{array}{c}\text { Maximum lateral } \\
\text { offset }\end{array}$ & 2 & 2 \\
\hline
\end{tabular}

Also the OV moves due to various operational conditions, although the OV displacements are much smaller than those of the PV, as shown in Table 1. The lateral movements of the $\mathrm{OV}$ with respect to the NBI box (which is fixed in the experimental hall) are $2 \mathrm{~mm}$ for both port AEK20 and AEK21. The relative displacements between OV and NBI-box are compensated by the NBI bellows unit, described in Section 4.

The OV-NBI relative displacements and PV-OV relative displacements have been summarized in Table 1. 
These values have driven the design of the bellows scraper and its support joints, as shown in Section 7.

\section{Gate valve}

A commercially available DN 800 gate valve with compressed air pneumatic actuator is installed on each of the W7-X NBI boxes to allow for separation of the PV vacuum from the NBI box vacuum. Each valve weighs about $740 \mathrm{~kg}$ and is made of stainless steel (mainly 316L or 1.4435) with low cobalt content and low magnetic permeability $\left(\mu_{\mathrm{r}}<1.05\right.$ for valve casing, $\mu_{\mathrm{r}}<1.08$ for welds), with a low portion of ferromagnetic material $(<10 \mathrm{~kg})$ in the driving mechanism. A special FKM Viton ${ }^{\circledR}$ O-ring of green color with reduced absorption of ECRH stray radiation, which has been tested at MISTRAL [10], has been installed on both valves as gate seal.

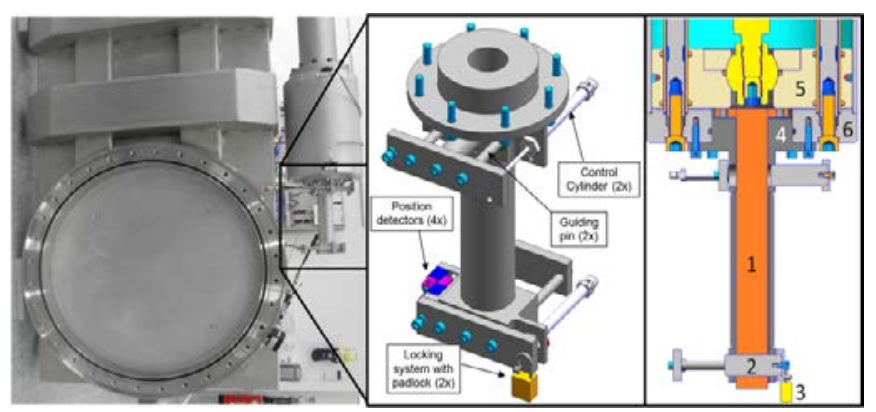

Figure 4: Left: DN 800 VAT gate valve with blocking device. Center: CAD model of blocking device. Right: section view of the blocking device with gate valve in "open” position (1) cylindrical stud, (2) transverse pin, (3) padlock, (4) blocking device casing, (5) valve driving cylinder, (6) casing of driving mechanism.

\subsection{Blocking device}

Both valves have been equipped with a custommade locking system which mechanically locks the valve in open or closed position. Additionally, end switches are used to communicate the state of the blocking device to the control system. This device has been designed to allow entrance into the vented W7-X PV while the NBI box is evacuated or into the vented NBI box while the PV is evacuated, as well as a safe access to W7-X through the NBI duct during machine maintenance. As shown in Figure 4, a cylindrical stud is rigidly fixed to, and therefore moves with, the cylinder that drives the pneumatic mechanism of the gate valve. When the driving cylinder is either at the "open" or "closed" position, a transversal pin, driven by a separate pneumatic system, can be inserted into the cylindrical stud to block it. The transverse pin will then be additionally fixed by means of a padlock before granting access to the PV or the NBI box. This ensures that the gate valve will not move, even if a wrong command is sent by a fault in the control system.

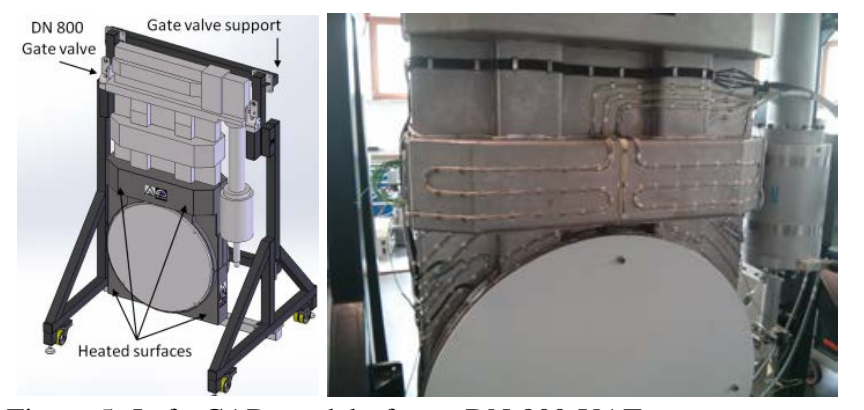

Figure 5: Left: CAD model of new DN 800 VAT gate on support structure with indication of heated surfaces. Right: detail of the new gate valve during testing of heating system, without thermal insulating jacket and with visible heating elements and cabling.

\subsection{Bake-out system}

Before starting plasma operation after a machine opening, the W7-X PV will be baked out at $150{ }^{\circ} \mathrm{C}$ for several days. The NBI gate valves form part of the PV and have consequently been equipped with a heating system, shown in Figure 5, that allows for a gradual $\left(10^{\circ} \mathrm{C}\right.$ per hour) and uniform $\left( \pm 10^{\circ} \mathrm{C}\right)$ heating of the lower part of the valve body. The NBI box will not be baked out, therefore the gate valve plates seal is positioned on the torus-side, which reduces the valve body portion to be baked out. Nevertheless, in order to minimize thermo-mechanical stresses, both flanges and surrounding valve body parts are being baked out. The heating system of each valve is made out of four separate heating circuits, each one heating up a specific part of the valve body. Redundant $6 \mathrm{~m}$ long heating elements are laid in a meander-like shape to distribute the heat more uniformly. A set of thermocouples (TCs) is installed on the valve bodies for temperature control and three thermal switches are installed in each circuit to protect the valve body from overheating in case of thermal runaway of a heating element due to a flaw in 
the heater control unit. The valve body is also covered with an insulating jacket, to reduce thermal losses and improve the temperature uniformity.

The gate valves, the baking device and the insulation have been procured by the Polish National Center for Nuclear Research (NCBJ) Otwock-Świerk, Poland, in the framework of a collaboration with W7-X [3]. The gate valves and blocking devices have been manufactured by the Swiss company VAT Vacuumventile AG, while the heating system has been provided by PREVAC sp. z o.o., Rogów, Poland.

\subsection{Electrical insulation}

During NBI operation, the NBI box can experience a transient voltage increase up to several hundred volts for a few $\mu \mathrm{s}$. This is due to occasional high voltage (HV) breakdowns between the grids of the extraction system which differ in potential by up to $60 \mathrm{kV}$. To avoid interference with the data acquisition systems, an electrical insulation is placed between the gate valve (electrically connected to the OV) and the NBI box. The insulation is obtained by a combination of a glass-fiberreinforced plastic plates on the air side of the connection and PEEK plates, sleeves and washers, with a typical thickness of $1 \mathrm{~mm}$, between gate valve and NBI box flanges as well as in the screwed connections to the NBI box. This setup ensures an electrical insulation up to $1.7 \mathrm{kV}$ potential difference, which has been tested on a small mock-up.

\section{NBI bellows unit}

The NBI bellows unit, used to connect the gate valve to the OV, is shown in Figure 6. The NBI bellows unit comprises a rotatable flange on the NBI-box side, a single layer DN $800 \mathrm{~mm}$ U-profile bellows and an oval diagnostic flange. The latter is mounted directly on the $\mathrm{OV}$ and integrates several diagnostics, described in Section 5. The stainless steel $0.5 \mathrm{~mm}$ thick bellows allows for a one-off adjustment of $\pm 5 \mathrm{~mm}$ in axial and $\pm 4 \mathrm{~mm}$ in lateral direction, to compensate for manufacturing and assembly tolerances and to allow for a proper alignment of NBI beams with respect to the NBI port which in turn reduces beam losses in the duct.
The bellows also allows for an additional displacement of $\pm 2 \mathrm{~mm}$ in lateral direction for 1000 cycles over the experimental lifetime of W7-X, to compensate for movements of the OV, e.g. during machine bake-out (see Table 1 for a comparison with the expected displacements). The bellows is protected on the outside by a fixed metal ring. For the installation of the NBI bellows unit, four adjustable mounting supports are used.

The two main flanges of the NBI bellows unit are double sealed using a Helicoflex ${ }^{\circledR}$ as primary seal and a Viton O-ring as a backup seal, with the possibility to pump the space in between the two seals.

In the diagnostic flange several ports and feedthroughs are installed to supply cooling water to the components installed inside the NBI port. Two DN $25 \mathrm{~mm}$ feedthroughs feed the cooling circuit for the IVC heat shields, while smaller DN $10 \mathrm{~mm}$ feedthroughs supply the bellows scraper cooling circuit.

CF flanges and silver-coated annealed copper gaskets are used for all water connections. For the small DN 10 CF connections custom-made gaskets, developed by the IVC group, have been used. These gaskets are screwed beforehand on the metal hose flanges for easier assembly in the limited available space.

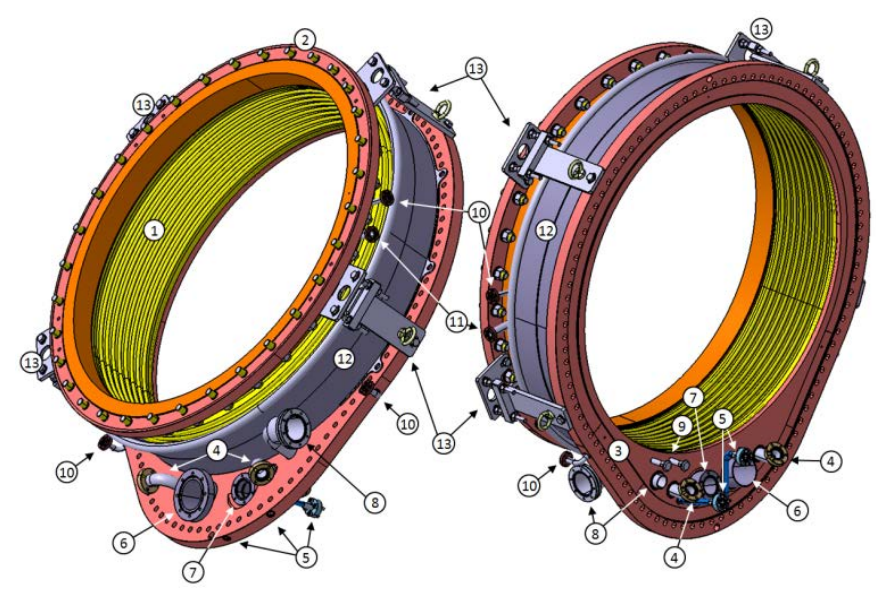

Figure 6: CAD model of the bellows unit: (1) DN 800 bellows, (2) rotatable flange, (3) diagnostic flange. Feedthroughs for: (4) IVC cooling water, (5) bellows scraper cooling water, (6) $\mathrm{H}_{\alpha}$ diagnostics, (7) borescope, (8) thermocouples. (9) studs for winding excess TC length, (10) ports for evacuation of space between Viton O-ring and Helicoflex seals, (11) port for pressure measurement in NBI duct, (12) protection ring, (13) adjustable mounting supports. 
The NBI bellows unit has been manufactured at the IPP workshop in Garching, with the exception of the large DN 800 bellows which has been provided by the Swiss company Kompaflex, using low-cobalt $(<500 \mathrm{ppm})$ and low-magnetic permeability $\left(\mu_{\mathrm{r}}<1.01\right)$ stainless steel.

\section{Diagnostics}

In the space between the NBI bellows unit and the bellows scraper (see Figure 3) a set of diagnostics is installed with the aim to monitor the beam and port walls and to avoid damages to the port due to re-ionized particles and direct beam interception. TCs are installed in several components for temperature measurement in critical areas. A borescope is used to acquire optical images, while an $\mathrm{H}_{\alpha}\left(\mathrm{D}_{\alpha}\right)$ diagnostics line-of-sight is implemented to detect beam blocking. The flange on the NBI-box side of the NBI bellows unit is also equipped with a DN 16 port to allow for measuring the port internal pressure.

\subsection{Thermocouples}

In total nine TCs are installed in each NBI port through the NBI bellows unit. Six TCs are positioned on the outer surface of the bellows scraper, two TCs are

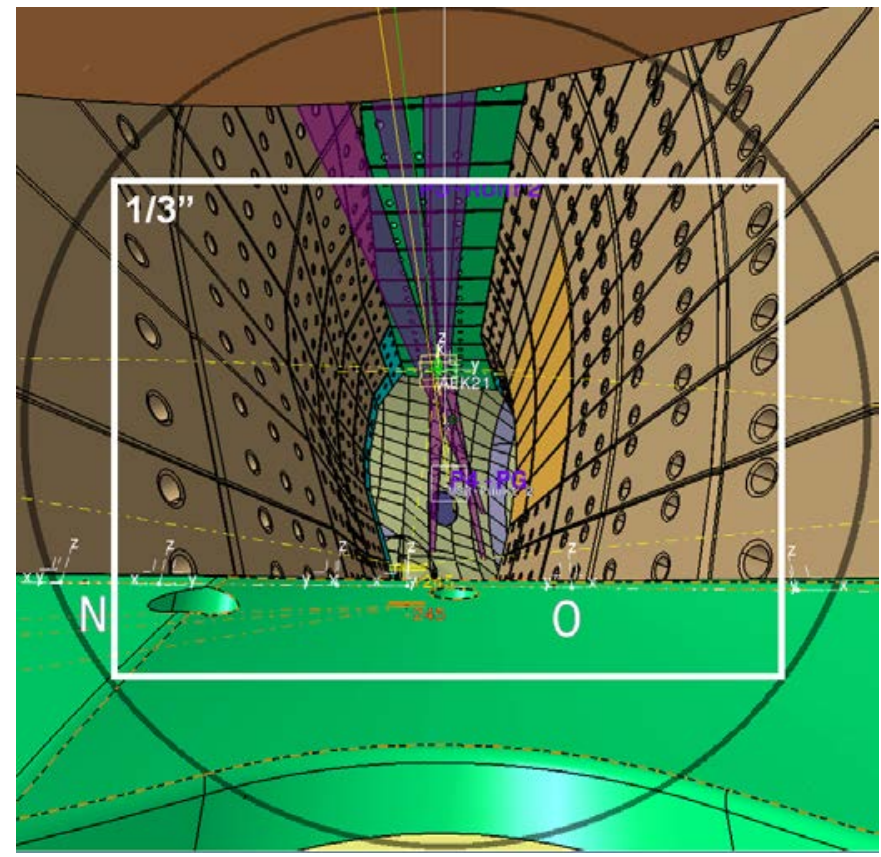

Figure 7: Field of view of the borescope in beam direction installed in the NBI port. The dark grey circle represents the available field of view 6 from the borescope optics, while the white rectangle corresponds to the field of view available using a 1/3" inch CCD screwed to the back-side of IVC copper supports of the heat shields, in the portion with the highest heat load, while one TC is brazed directly onto the port bellows to monitor possible heating of the thin bellows (a few tenths of mm thick) due to ECRH stray radiation, which could be particularly intense in some ECRH-W7-X operational scenarios. All these TCs are routed to a DN 50 CF flange, equipped with LEMO feedthroughs, mounted on the diagnostic flange of the NBI bellows unit.

\subsection{Borescope}

A $500 \mathrm{~mm}$ long immersion pipe with a borosilicate glass window and an Olympus ${ }^{\mathrm{TM}}$ borescope (with $90^{\circ}$ angle of view) inside are installed in the NBI bellows unit diagnostic flange, as shown in Figure 3. The borescope is positioned in the air side and is connected to an optical CCD camera to allow for monitoring of a large area of the port walls and a portion of the PV inner wall, as shown in Figure 7.

Like the rest of the port components, the borescope has to withstand a temperature of $150{ }^{\circ} \mathrm{C}$ for several days during machine bake-out. This is however not guaranteed for standard optical products. Therefore, the borescope has been equipped with a custom air-cooled tube that keeps the borescope at acceptable temperature up to a surrounding temperature of $220^{\circ} \mathrm{C}$. The CCD camera will be removed from outside before machine bake-out. Removal of the borescope after final machine assembly can be done only from inside the NBI port, by demounting the immersion pipe through the narrow bellows scraper service plate (see Section 7). In case of a leak in the immersion tube, an external fitting can be installed on the outer borescope flange to allow for pumping the immersion tube from outside and enable continuity of W7-X operation.

\section{3 $\quad \mathrm{H}_{\alpha}$ diagnostic}

An optical lens system is installed in the NBI bellows unit diagnostic flange and connected to a spectrometer in order to measure $\mathrm{H}_{\alpha}$ emission in the NBI duct. This diagnostic tool is an important safety device that can quickly detect beam blocking and switch off the 
neutral particle beam (within $50 \mathrm{~ms}$ ) before the port walls are damaged. Beam blocking is an effect caused by re-ionization of a portion of the fast neutral particles of the beam due to collisions with the background gas. The trajectories of re-ionized particles in the beam are bent towards the port walls by the stellarator's magnetic field. If the surfaces heated by the re-ionized particles release a considerable amount of gas into the beam path, the resulting positive feedback can lead to complete beam blocking. This in turn can produce a very high head load in localized regions of the port wall, causing damage or melting of components. By a combination of baking at high temperature $\left(150^{\circ} \mathrm{C}\right)$ and gradual increase of beam power during NBI start-up, while monitoring the intensity of the $\mathrm{H}_{\alpha}$ beam emission in the NBI port, it is possible to condition the port walls and avoid beam

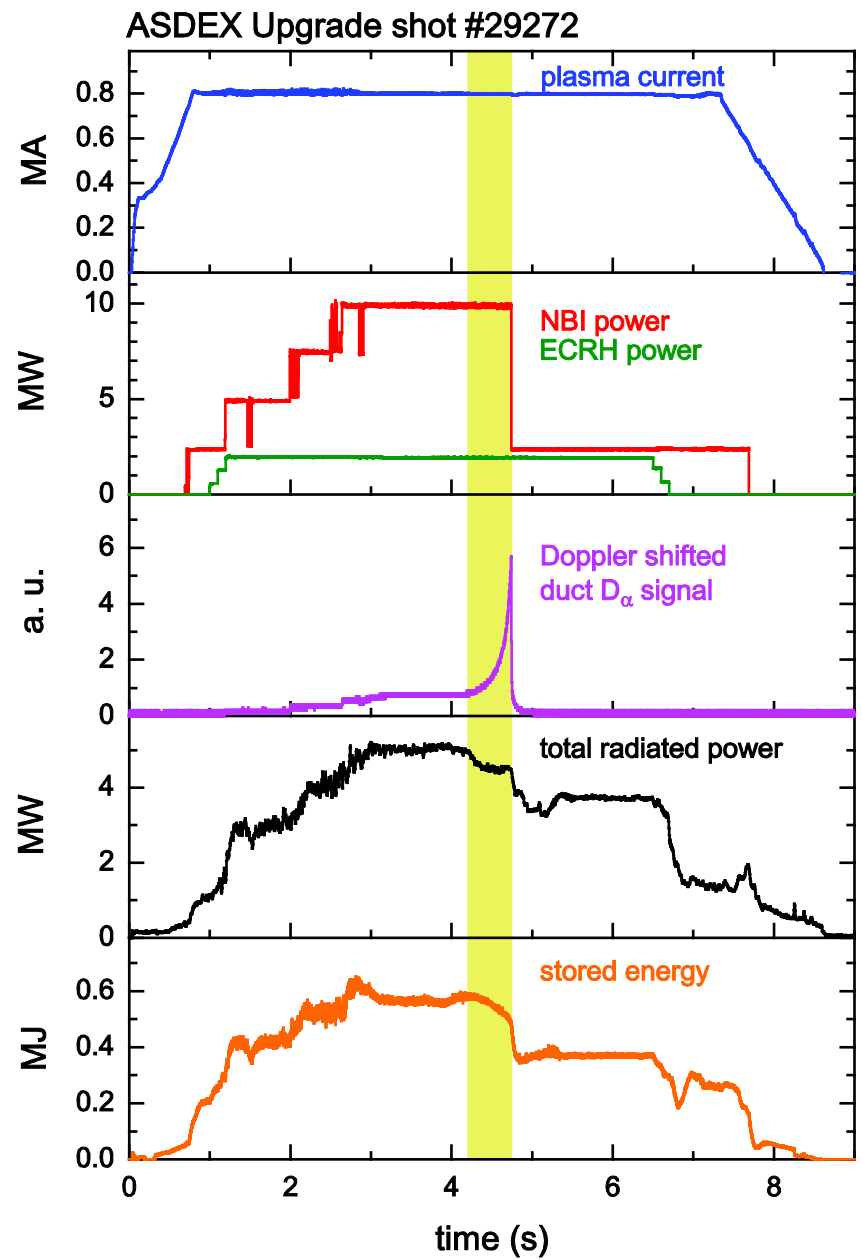

Figure 8: Diagrams of an AUG discharge during which the neutral beams of one beam line were switched off by the $\mathrm{D}_{\alpha}$ interlock. blocking.

Figure 8 shows diagrams of an AUG discharge during which the neutral beams of one beam line were switched off by the $D_{\alpha}$ interlock. From 0.7 to $2.6 \mathrm{~s}$ four NBI beams with a heating power of $2.5 \mathrm{MW}$ each are successively switched on, one from beam line 1 and three from beam line 2. ECRH with $2 \mathrm{MW}$ is also used and its power is held constant from about 1.2 to $6.5 \mathrm{~s}$. At around $4.2 \mathrm{~s}$ the Doppler shifted $\mathrm{D}_{\alpha}$ signal in the duct of beam line 2 starts to increase and the interlock is finally triggered at $4.74 \mathrm{~s}$, switching off the three beams of that beam line. It is interesting to note that both the total radiated power from the plasma as well as the plasma's stored energy visibly decrease while the duct $\mathrm{D}_{\alpha}$ signal increases. This indicates that the NBI power to the plasma decreases as more and more power is lost to the duct walls by re-ionized beam neutrals.

By analyzing the beam emission Doppler shift, beam spectroscopy is also used to evaluate beam divergence and the fractions of $\mathrm{H}$ atoms in the neutral beam at $1 / 2$ or $1 / 3$ of the nominal energy (in AUG usually in the range of $29 \%$ and $21 \%$ respectively) due to the extraction of $\mathrm{H}_{2}^{+}$and $\mathrm{H}_{3}{ }^{+}$from the ion source. These numbers are important to estimate the beam penetration depth profile in the plasma.

\section{Box exit scraper}

At the exit of the NBI box a BES is installed to protect the NBI box and gate valve flanges from the heat loads generated by direct beam interception. The BES, shown in Figure 9, consists of four copper parts, with a thickness typically in the range of $20 \mathrm{~mm}$, which have been forged and machined into a shape that minimizes the heat load density from the beam. The BES is inertially cooled (i.e. mainly between the beam pulses) by a water circuit made of a $13 \mathrm{~m}$ long $12 \mathrm{x} 1 \mathrm{~mm}$ stainless steel pipe. The copper parts and the cooling pipe are vacuum-brazed together using a Ni-based braze in one brazing process. The BES is fixed to the inside of the NBI box by means of three stainless steel joints. The design integrates two pipes for endoscopes that allow for visual inspection of the inner NBI duct surfaces. 


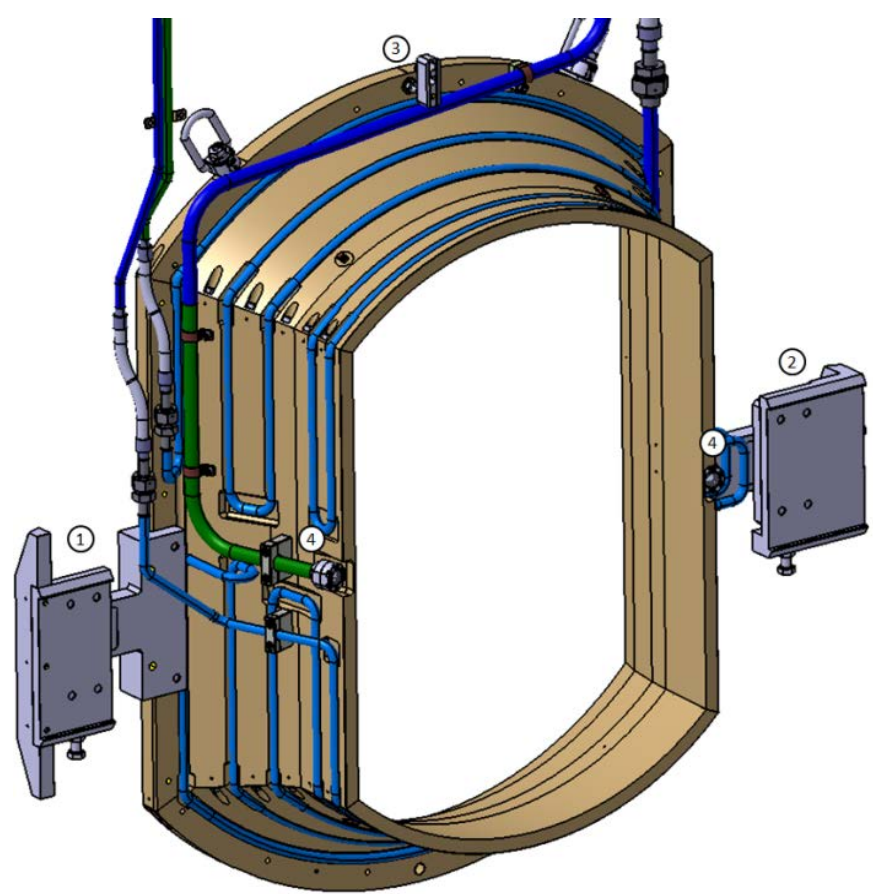

Figure 10: CAD model of box exit scraper: (1) pin joint, (2) sliding support, (3) vertical support and (4) endoscope pipes for NBI duct inspection.

For temperature monitoring during beam injection, four TCs are installed on the outer surfaces of the BES. The BES is manufactured using OFHC copper and lowcobalt, low magnetic permeability stainless steel $\left(\mu_{\mathrm{r}}<1.01\right)$. Each BES weights about $150 \mathrm{~kg}$ and has been manufactured by De Pretto Industrie S.r.l., Schio, Italy.

\section{Bellows scraper}

In order to protect the NBI bellows unit and the port bellows from heat load due to re-ionized particles and direct beam interception, a bellows scraper is installed in the NBI port, as shown in Figure 3. The bellows scraper consists of a copper cone with a typical thickness of $20 \mathrm{~mm}$ which is inertially cooled by a water circuit, similarly to the BES. The cooling circuit is made of a $13.5 \mathrm{~m}$ long $12 \times 1 \mathrm{~mm}$ stainless steel pipe. The bellows scraper is manufactured by vacuum brazing together five copper panels and the cooling pipe in the same brazing process, using a Ag-Cu braze. The design includes a service plate to allow for access to diagnostics and pipe connections in the NBI bellows unit. Special care has

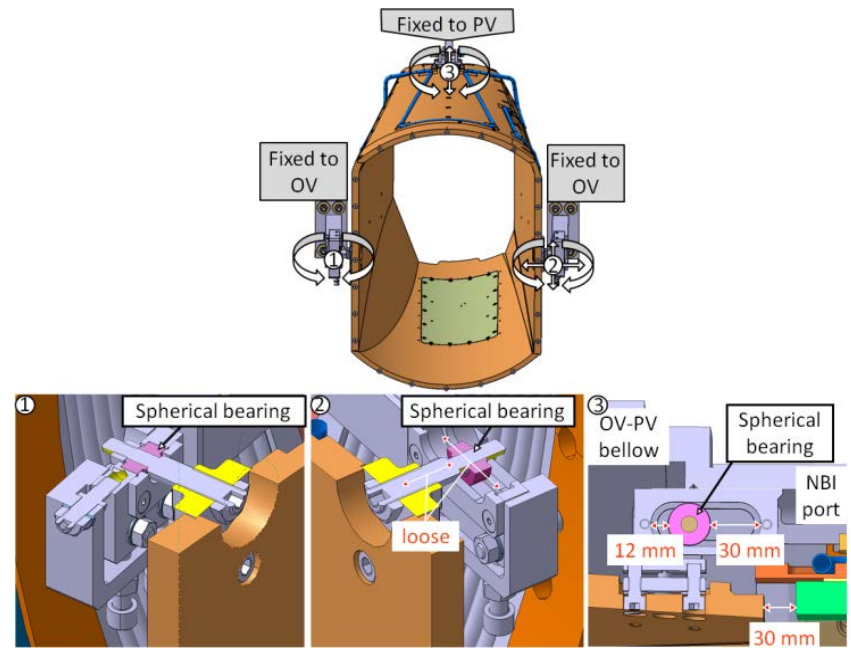

Figure 9: Top view of the bellows scraper and detail of supports: bearing A (1) allows for an adjustment of the bellows scraper position of $\pm 5 \mathrm{~mm}$ in all directions. Once adjusted, it acts as a fixed point with free rotation. Bearing B (2) can be adjusted by $\pm 5 \mathrm{~mm}$ in vertical direction and allows for a rotation around bearing $A$. Bearing $C$ (3) can be adjusted by $\pm 3 \mathrm{~mm}$ in vertical and transversal directions and allows for $-12 \mathrm{~mm} /+30 \mathrm{~mm}$ axial displacement ("+" meaning that port moves towards bellows scraper). All joints include a spherical bearing, the bellows scraper is therefore isostatically constrained.

been taken in the design of the water connections and supports for metal hoses for the cooling circuit to avoid intersections with the $\mathrm{H}_{\alpha}$ diagnostic line-of-sight.

Three joints (bearing A, B, C) are integrated in the design of the bellows scrapper, as visible in Figure 10. The bearing $\mathrm{A}$ and $\mathrm{B}$ join the bellows scraper to the $\mathrm{OV}$, while the bearing $\mathrm{C}$ joins it to the PV. This ensures that the bellows scraper can adapt to the relative movements
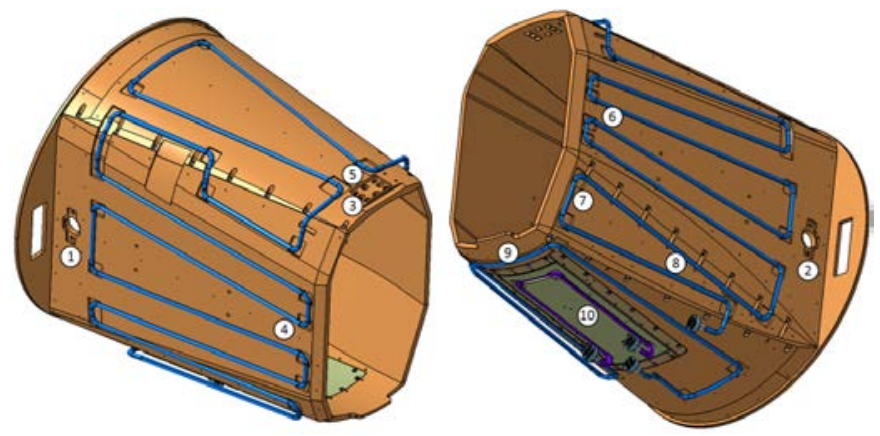

Figure 11: $C A D$ model of the bellows scraper: boreholes for bearing $A$ (1), $B$ (2) and $C$ (3). For thermal monitoring, 6 thermocouples have been integrated in the design and installed (4-9). A service plate (10) is used to access diagnostics and water connections of the NBI-torus interface. 

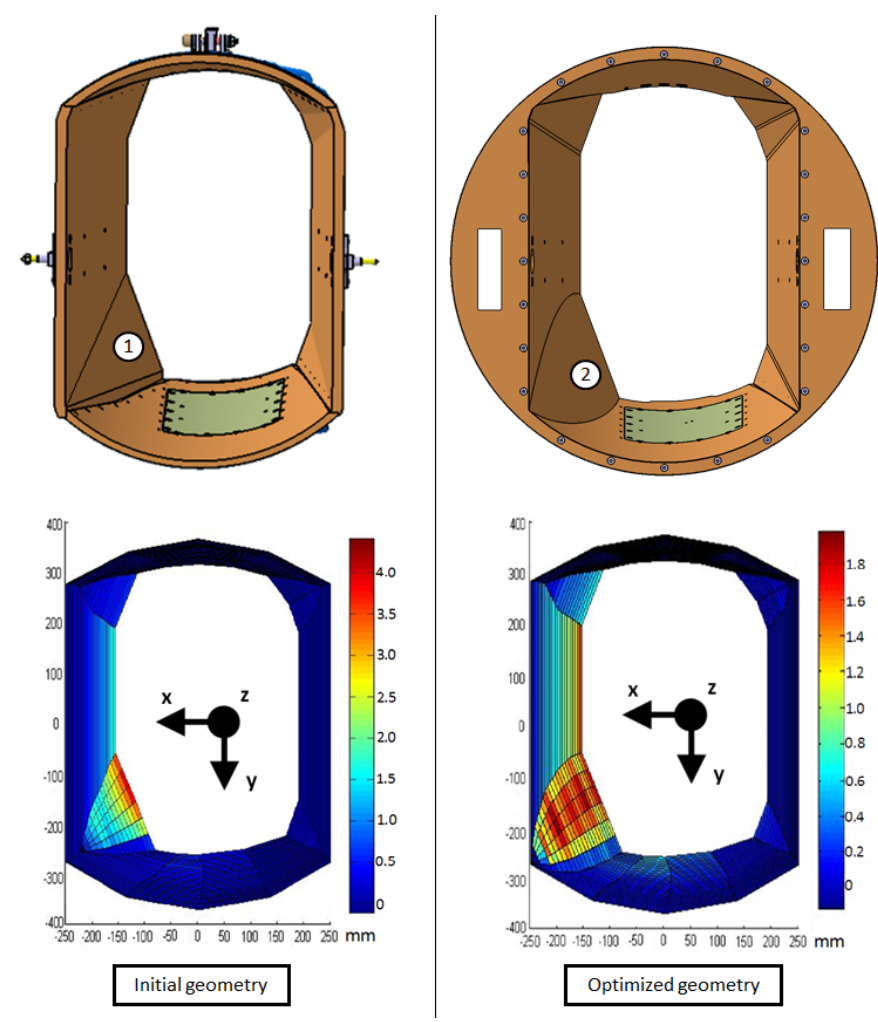

Figure 12: Frontal projection of the power load densities on the inner surface of the bellows scraper: initial geometry (left) with flat "wedge” (1) and after optimization (right), with curved wedge (2) and additional shield. Power load densities in $M W / m^{2}$, dimensions in $\mathrm{mm}$ (left and right diagrams have different scales).

of PV and OV. The bearings A and B (C) allow for an initial adjustment of \pm 5 (3) $\mathrm{mm}$ in all directions to compensate for machining and assembly tolerances.

To monitor the bellows scraper temperature during beam injection, six TCs are installed on the outer surfaces of the copper cone, in correspondence to points where higher heat loads are expected, as shown in Figure 11.

The bellows scraper has been manufactured by SDMS la chaudronnerie blanche ${ }^{\circledR}$, Saint Romans, France, using OFHC copper for the copper parts and low-cobalt, low-magnetic permeability stainless steel $\left(\mu_{\mathrm{r}}<1.01\right)$ for the cooling pipes and supports.

\subsection{Bellows scraper shape optimization}

Due to the 3-dimensional NBI port geometry, the shape of the bellows scraper is relatively complex, although still machinable by modern 5-axis CNC machine tools. In addition, a local restriction of the port section, caused by a close non-planar superconducting magnet, means that the bellows scraper intercepts a portion of the beam power. As a consequence, a localized high heat load is present in part of the inner wall of the bellows scraper.

The most critical point is the "wedge" shown in Figure 12, which is positioned in correspondence with the projection of the sources 1 and 5 in the NBI injectors NI20 and NI21 respectively [8].

The beam power transmission and the power load density along the NBI port have been calculated using the DENSB code, developed in-house at IPP [11].

In a first design stage the wedge was shaped as a flat surface. In this preliminary design, the calculated power load on the wedge produced by an NBI injector equipped with 4 sources (i.e. $10 \mathrm{MW}$ power in D) was about $4 \mathrm{MW} / \mathrm{m}^{2}$, as shown in Figure 12, which results in a maximum temperature above the melting point of copper for a $10 \mathrm{~s}$ beam. This design would have

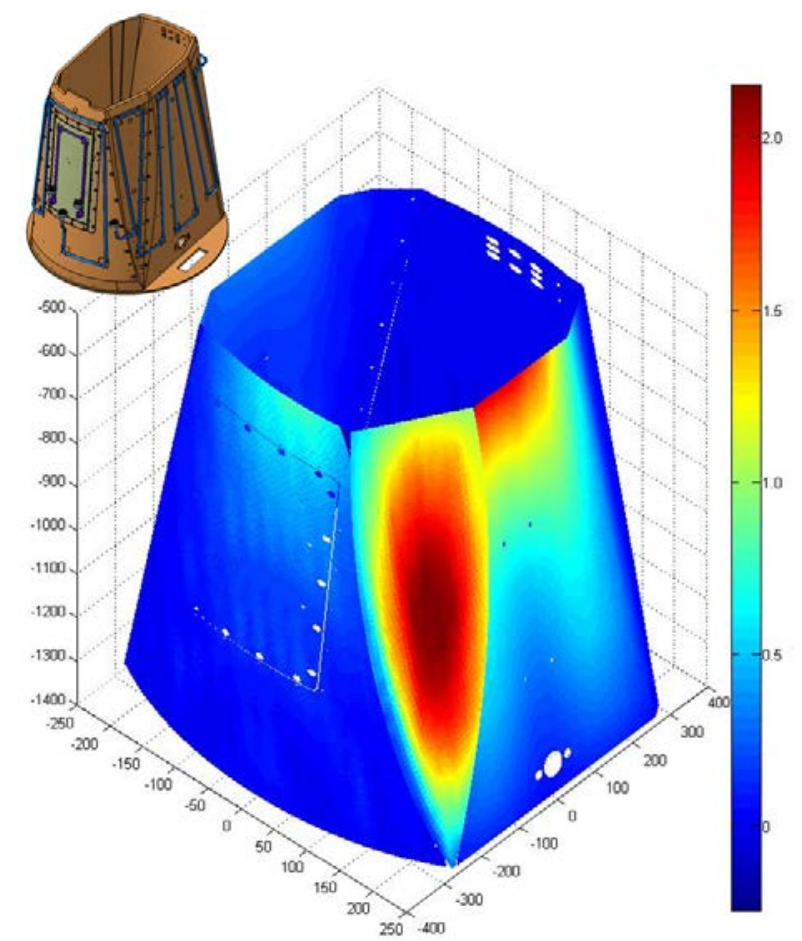

Figure 13: Isometric view of the power load densities on the inner surface of the bellows scraper with optimized final geometry. Maximum power load density is $2.1 \mathrm{MW} / \mathrm{m}^{2}$, dimensions in $\mathrm{mm}$. 
produced a strong limitation of the NBI operation power and beam-on time. A design optimization has been undertaken with the aim to reduce the maximum temperature of the bellows scraper to a maximum of $400{ }^{\circ} \mathrm{C}$.

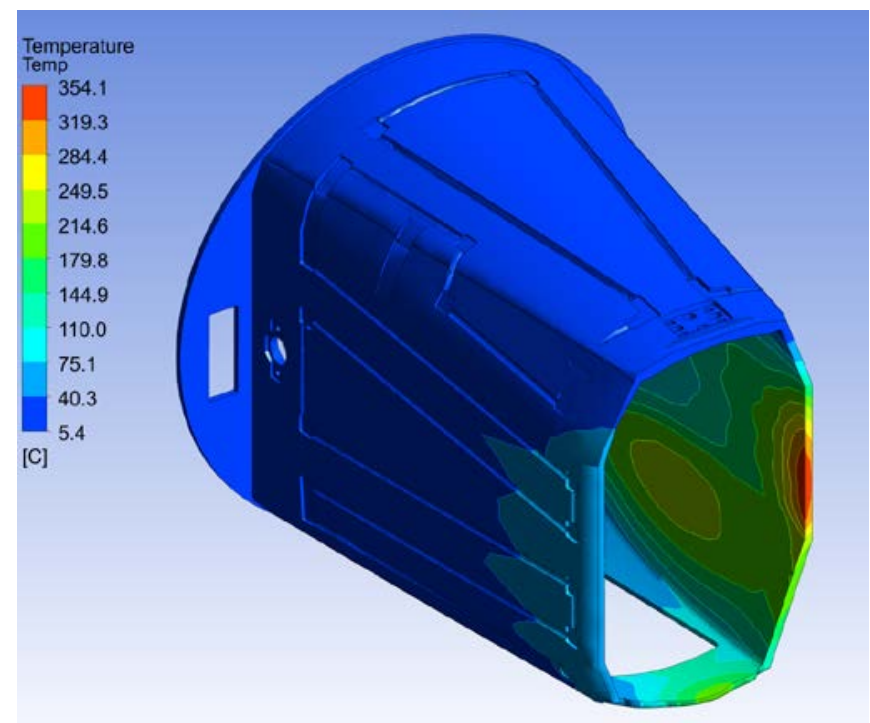

Figure 14: Temperature distribution in the bellows scraper at the end a $10 \mathrm{MW}, 10 \mathrm{~s}$ beam pulse.

The 3-dimensional power load density was imported from DENSB into MATLAB $\AA$, where a simplified parametric model of the inner surface of the bellows scraper was produced. The power load density projected on the bellows scraper was calculated for several possible geometries. With this process it was possible to iteratively approach an optimal shape of the bellows scraper inner surface which minimizes the power load on the critical areas and at the same time is still simple enough and reasonably economical to manufacture. The result is an inner wedge surface with a cylindrical shape of $4000 \mathrm{~mm}$ radius.

The final geometry of the bellows scraper inner surface has then been modeled using the CAD program CATIA ${ }^{\circledR}$ and finely meshed (element size $\approx 10 \mathrm{~mm}$ ) using the commercial FE code ANSYS ${ }^{\circledR}$. This optimized model of the bellows scraper inner surface has finally been used to perform a more precise calculation by MATLAB of the power deposition distribution, visible in Figure 13. The outer contour of the bellows scraper, and in particular of the wedge, has been kept as in the original geometry, therefore increasing the thickness to about $45 \mathrm{~mm}$ in the area of the wedge corresponding to the maximum heat load. The maximum temperature at the end of a $10 \mathrm{MW}, 10 \mathrm{~s}$ beam pulse, calculated by FEM, is about $350^{\circ} \mathrm{C}$, as shown in Figure 14.

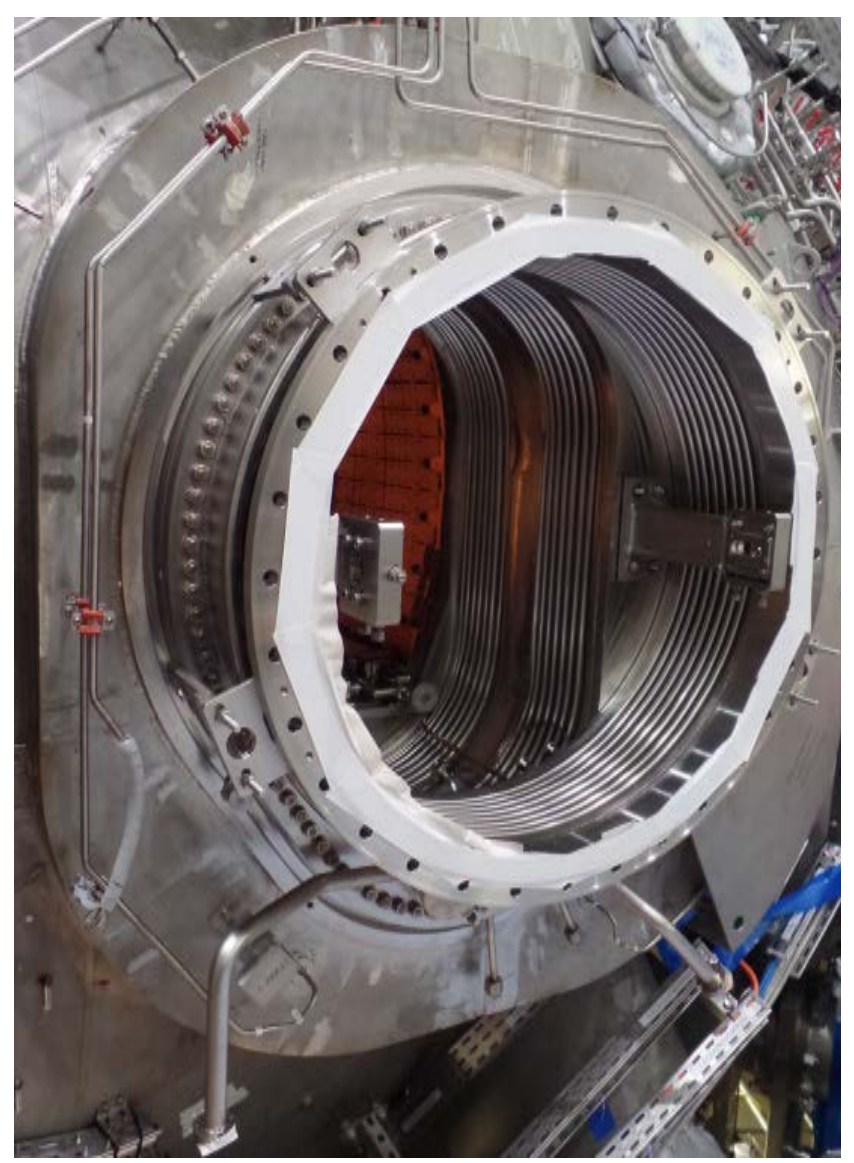

Figure 15: NBI bellows unit installed on the AEK21 port of W7-X.

\section{Current status}

Assembly of the components for the NBI-torus interface started in 2013 with the mounting of the gate valves and electrical insulations on the NBI boxes in the NBI assembly hall at IPP Greifswald. Mounting of NBI bellows units and bellows scrapers on W7-X has been completed by 2014. Figure 15 and Figure 16 show the components installed on the port AEK21. The NBI boxes have been connected to W7-X and aligned with respect to the NBI ports by means of three targets mounted inside the ports and lasers fixed to the PINI flanges. Final adjustment has been completed by the end 


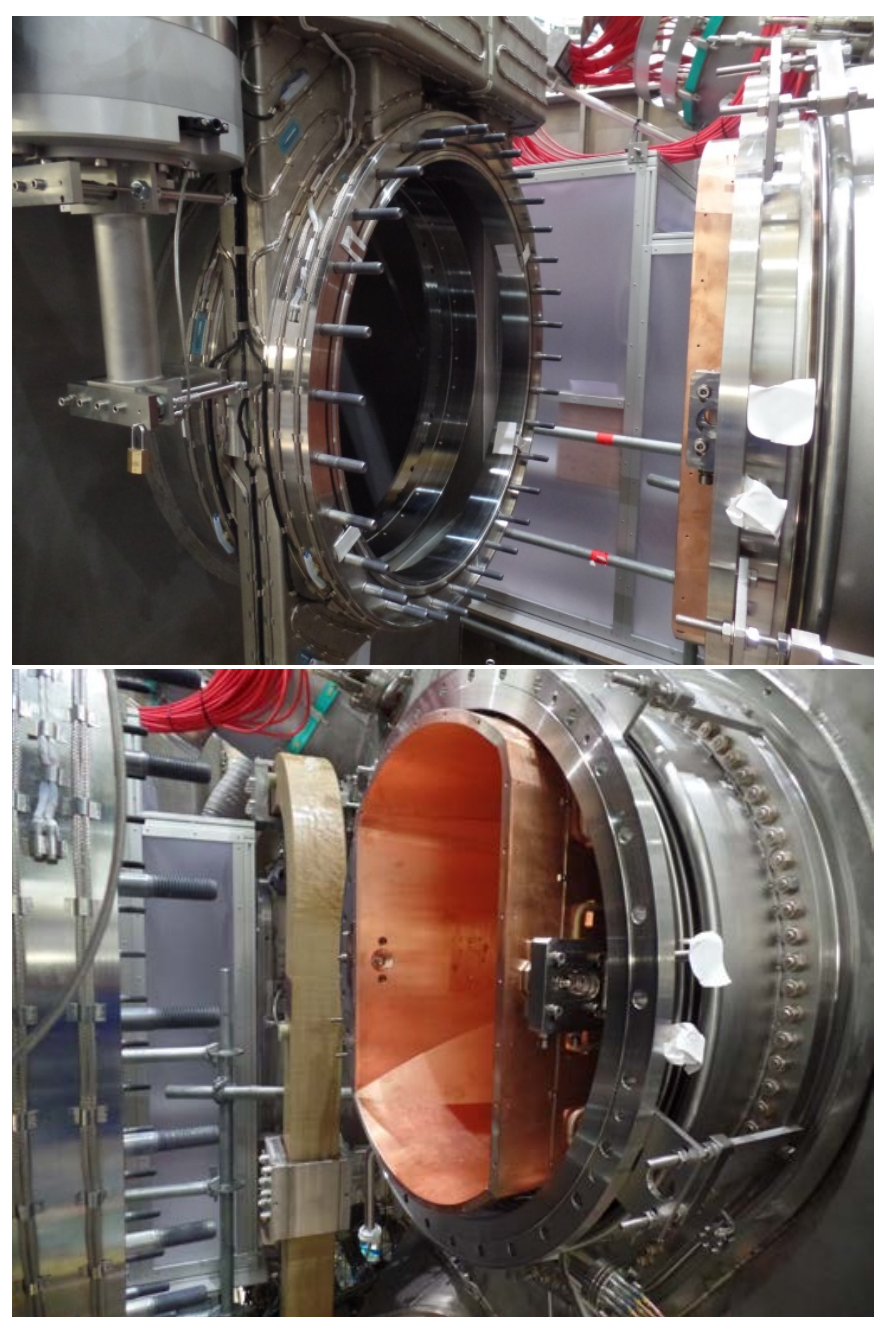

Figure 16: NBI-torus interface of AEK21 port ready for final assembly.

of 2014. The BESs are planned to be installed inside the NBI boxes in April 2015.

\section{Conclusions}

For the NBI heating system at W7-X a new NBItorus interface has been designed, manufactured and almost completely installed. Although the W7-X NBI system is based on the one in use on AUG, the NBItorus interface components have been completely redesigned to adapt them to the complex geometry of W7-X and to PV and OV movements, especially during machine bake-out. The NBI-torus interface consists of a gate valve, electrically insulated from the NBI box and equipped with a blocking device and a bake-out heating system, and a NBI bellows unit, which integrates several beam diagnostics and a bellows that compensates the movements of the OV. The NBI duct is protected from re-ionized particles and direct beam interception by inertially cooled scrapers, which have been designed to allow injection of a $10 \mathrm{MW}$ beam for $10 \mathrm{~s}$. The bellows scraper, which compensates for relative displacements between OV and PV during several operation scenarios, especially during machine bake-out, has been optimized with a numerical procedure to limit maximum temperature at the end of the beam to $350{ }^{\circ} \mathrm{C}$.

\section{Acknowledgments}

This project has received funding from the European Union's Horizon 2020 research and innovation programme under grant agreement number 633053. The views and opinions expressed herein do not necessarily reflect those of the European Commission.

\section{References}

[1] H.-S. Bosch, V. Erckmann, R. W. T. König, F. Schauer, R. J. Stadler and A. Werner, „Construction of Wendelstein 7-X - Engineering a Steady State Stellarator“, IEEE Trans. Plasma Sci., Vol. 38, No. 3 (2010) pp. 265-273.

[2] T. Bräuer, T. Klinger and H.-S. Bosch, „Progress, challenges, and lessons learned in the construction of Wendelstein 7-X,“ IEEE Trans. Plasma Sci., Vol. 40, No. 3 (2012) pp. 577-583.

[3] G. Duesing, H. Altmann, H. Falter, A. Goede, R. Haange, R. S. Hemsworth, P. Kupschus, D. Stork, E. Thompson, "Neutral beam Injection System," Fusion Technology, vol.11, (1987) pp. 163-202.

[4] P. McNeely, M. Barlak, J. Baldzuhn, S. Bozhenkov, M. Drevlak, G. Gawlik, B. Heinemann, D. Holtum, J. Jagielski, R. Kairys, R. Nocentini, R. Riedl, P. Rong, N. Rust, R. Schroeder, E. Speth, A. Stäbler, A. Turos, R. Wolf, "Current status of the neutral beam heating system of W7-X,” Fus. Eng. Des. 88 (2013) pp. 1034-1037.

[5] A. Stäbler, J.-H. Feist, E. Speth, J.L. Dunne, S. Goetz, B. Heinemann, A. Krauss, R.-C. Kunze, H. Lohnert, J. Sielanko, W. Szyszko, O. Vollmer, K. Wittenbecher., „Design of the neutral beam 
injection system for ASDEX-Upgrade,“ Fusion Technology (1988) pp. 620-624.

[6] B. Heinemann, B. Sombach, J-L. Dunne, W. Ertl, J.-H. Feist, K. Freudenberger, R. Riedl, E. Speth, A. Stäbler, O. Vollmer, "Manufacturing and Assembly of the Neutral beam injector for ASDEXUpgrade,” Fusion Technology (1992) pp. 524-528.

[7] G. Orozco, M. Froeschle, B. Heinemann, C. Hopf, R. Nocentini, R. Riedl, A. Stäbler, „AC operation of large titanium sublimation pumps in a magnetic field: Results of the test stand for the W7-X neutral beam injectors, “ Fus. Eng. Des. 89 (2014) pp. 30703077.

[8] N. Rust, B. Heinemann, B. Mendelevitch, A. Peacock, M. Smirnow, "W7-X neutral-beaminjection: Selection of the NBI source position for experiment start-up,” Fus. Eng. Des. 86 (2011) pp. 728-731.

[9] A. Peacock, J. Boscary, M. Czerwinski, G. Ehrke, H. Greuner, P. Junghanns, B. Mendelevitch, M. Smirnow, R. Stadler, H. Tittes and J. Tretter, "Status of High Heat Flux Components at W7-X," IEEE Trans. on Plasma Sci., Vol. 42, No. 3, (2014) pp. 524-532.

[10] D. Hathiramani, R. Binder, R. Brakel, T. Broszat, B. Brucker, A. Cardella, M. Endler, K. Grosser, M. Hirsch, H. Laqua and S. Thiel, "Microwave stray radiation, measures for steady state diagnostics at Wendelstein 7-X," Fus. Eng. Des. 88 (2012) pp. 1232-1235.

[11] F. P. Penningsfeld, “DENSB Code," IPP Report/229, Max Planck Institute for Plasma Physics, Garching (1986). 